\title{
Deciphering early-warning signals of SARS-CoV-2 elimination and resurgence from limited data at multiple scales
}

\author{
Kris V Parag ${ }^{1, *}$, Benjamin J Cowling ${ }^{2}$ and Christl A Donnelly ${ }^{1,3}$ \\ ${ }^{1} \mathrm{MRC}$ Centre for Global Infectious Disease Analysis, Imperial College London, London, UK \\ ${ }^{2}$ WHO Collaborating Centre for Infectious Disease Epidemiology and Control, School of Public Health, \\ The University of Hong Kong, Hong Kong, China \\ ${ }^{3}$ Department of Statistics, University of Oxford, Oxford, UK \\ *For correspondence: k.parag@imperial.ac.uk
}

\begin{abstract}
Inferring the transmission potential of an infectious disease during low-incidence periods following epidemic waves is crucial for preparedness. In such periods, scarce data hamper existing inference methods, blurring early-warning signals essential for discriminating between the likelihoods of resurgence versus elimination. Advanced insight into whether elevating caseloads (requiring swift community-wide interventions) or local elimination (allowing controls to be relaxed or refocussed on case-importation) might occur, can separate decisive from ineffective policy. By generalising and fusing recent approaches, we propose a novel early-warning framework that maximises the information extracted from low-incidence data to robustly infer the chances of sustained local-transmission or elimination in real time, at any scale of investigation. Applying this framework, we decipher hidden disease-transmission signals in prolonged low-incidence COVID-19 data from New Zealand, Hong Kong and Victoria, Australia. We uncover how timely interventions associate with averting dangerous resurgent waves, support official elimination declarations and evidence the effectiveness of the rapid, adaptive COVID-19 responses employed in these regions.
\end{abstract}

Keywords: COVID-19; SARS-CoV-2 elimination; effective reproduction numbers; infectious diseases; local transmission; imported cases; second waves.

\section{Introduction}

The timeliness of the application and relaxation of non-pharmaceutical interventions (NPIs) (e.g., border closures, quarantines or social-distancing mandates) has been a polarising and pressing topic of global debate throughout the COVID-19 pandemic. Deciding on how best to balance the risk of resurging infections (second or later waves) against the costs (economic and otherwise) of sustaining NPIs and related restrictions is non-trivial and lacks clear

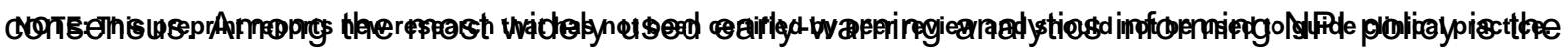


medRxiv preprint doi: https://doi.org/10.1101/2020.11.23.20236968; this version posted July $9,2021$. The copyright holder for this preprint
(which was not certified by peer review) is the author/funder, who has granted medRxiv a license to display the preprint in perpetuity. It is made available under a CC-BY-NC-ND 4.0 International license.

effective reproduction number $(R)$ [1,2], popularly displayed on numerous COVID-19-related websites and dashboards [3-6]. While, in theory, an escalation from $R<1$ (the epidemic is waning) to $R>1$ (it is growing) forewarns of resurgence, robustly and reliably identifying this transition when case-incidence is small is fundamentally difficult, in practice [7-9].

Low-incidence periods contain necessarily scarce data, which hamper standard $R$-inference approaches, limiting their reliability or forcing them to rely excessively on prior assumptions $[1,7,10,11]$. However, trustworthy disease-transmission estimates during those periods, which are characteristic of the lull between potential epidemic waves for example, are crucial for informing decision-making, providing early indicators for discriminating between the starkly different possibilities of elimination (i.e., no future local cases [2,12]) and resurgence. Inferring transmission dynamics at low incidence has been highlighted as a key challenge to designing safe protocols for NPI relaxation across the pandemic [11].

These problems are only exacerbated by the important and distinct roles of local and imported cases, both in controlling the chances of elimination or resurgence, and in defining effective NPI policy [2]. At low incidence, it is essential to distinguish between (i) true second waves of community transmission, which may necessitate broad-spectrum NPIs e.g., local lockdowns, and (ii) multiple, stuttering epidemic chains seeded by repeated importations, which require targeted NPIs e.g., isolation of travellers. Failing to properly account for local-import dynamics can inflate $R$-estimates, confounding (i) with (ii) and potentially misleading policymakers [13].

Moreover, estimating the likelihood of elimination and hence the endpoint of a local epidemic is non-trivial. While the World Health Organisation (WHO) recommends waiting fixed, diseasespecific times (28 days for COVID-19), from the last observed case, before declaring an outbreak over [12], this approach is insensitive to variations among incidence curves of the same disease [14] and neglects local-import case distinctions [15]. Recent methods, which better incorporate epidemic data to derive tailored and contextualised measures of elimination, however, are still intrinsically hindered by the poor reliability of $R$-estimates at the epidemic tail [15]. Consequently, more robust, data-driven outbreak analytics are needed to bolster NPI policy and decision-making during critical low-incidence periods [11].

Here we present a novel early-warning framework for robustly assessing $R$ and the likelihood of elimination, which circumvents the above problems, highlights the diverse roles of imported and local cases and underscores how well-timed, adaptive NPI application and relaxation can avert resurgence and promote local elimination. Our framework introduces two analytics: the smoothed local $R$ and $Z$ numbers, which measure community transmission and the confidence 
medRxiv preprint doi: https://doi.org/10.1101/2020.11.23.20236968; this version posted July 9 , 2021. The copyright holder for this preprint

in local elimination, respectively, at any time and scale of interest. Our $R$ improves on widelyused approaches such as EpiEstim [7] and the Wallinga-Teunis method [10] by generalising new methodology [16] that solves what is termed the smoothing problem in engineering [17], to include the local-import model previously used to investigate (i)-(ii) for zoonoses [18].

Smoothing solutions formally maximise the signal extracted from noisy datasets $[17,19]$. Our $R$-estimates exploit both forward- and backward-looking information from a given incidence curve (see Methods). Standard approaches use only forward- [10] or backward-looking [7] information, which limits their ability to decipher crucial trends hidden in the data. As a result, our R-estimates (Eq.1) are significantly more robust in low-incidence periods (see Results) and accordingly better at providing reliable, advanced warnings of resurgence. Our $Z$ number extends recent methods for forecasting epidemic lifetimes [15] to exploit these smoothed local $R$-numbers and to improve the quantification of uncertainty in their estimates (Eq.2). The result is a meaningful measure of our confidence at any time-point that there will be no future local cases i.e., that the epidemic is eliminated.

Our $R-Z$ framework can therefore expose transmission signals buried in scarce data to provide early risk-assessments of resurgence or confirmations of elimination. As it only requires local and imported case classifications, this framework can be applied at any scale (e.g., countrywide or sub-regionally) in real-time or retrospectively. We showcase its power by evaluating the alignment of NPI policy and key COVID-19 transmission dynamics in New Zealand, Hong Kong and Victoria state, Australia. While the demographics, epidemic curves and policies in these case-studies differ, all feature prolonged durations of low-incidence and appreciable case-importations that have stymied previous attempts at extracting insight into the interplay among NPIs and transmission potential [1,3-6]. Our analysis bolsters the evidence base for the effectiveness and timeliness of the strategies each location employed.

\section{Results}

We examine three case studies involving local COVID-19 dynamics for New Zealand, Hong Kong and Victoria state, Australia. Our main results are in Figures 1-3. While the $Z$ metrics are always computed sequentially in real time, the $R$-estimates shown below are retrospective as we process the entire incidence curve over our study period. This means that they present the most informative view of transmission possible (see Methods). We provide corresponding real time $R$-estimates in the Supplement (Figures $A, D$ and $G$ ), which only process portions of the incidence curve up to key intervention timepoints. These analyses largely correspond with Figures 1-3 (usually agreeing within 3 days of additional data), and underscore the benefit of our framework for deciphering key early-warning signals of transmission dynamics. 
medRxiv preprint doi: https://doi.org/10.1101/2020.11.23.20236968; this version posted July 9 , 2021. The copyright holder for this preprint (which was not certified by peer review) is the author/funder, who has granted medRxiv a license to display the preprint in perpetuity. It is made available under a CC-BY-NC-ND 4.0 International license .

\section{Elimination and import-driven resurgence in New Zealand}

New Zealand recorded local transmission of the SARS-CoV-2 virus in mid-March of 2020 and, within 2 weeks, initiated border closures (19 March) and devised a 4-level alert system for NPI deployment, with the aim of elimination [20]. Elevated caseloads quickly culminated in national lockdown (level 4) on March 26, which involved stay-at-home orders and wide venue closure. As the epidemic waned, NPIs were relaxed by May 14 (level 2), although social distancing remained enforced. Subsequently, no cases were observed for a prolonged period leading to a declaration of elimination on June 9 (level 1) [20]. However, local cases were detected again in early August and NPIs (e.g., contact bubbles and work at home orders) were swiftly enacted by August 12 to avoid resurgence (levels 2-3). De-escalation (level 1) followed on October 7; the last date we analyse. Figure 1 (top) summarises this case timeline with data from [21].
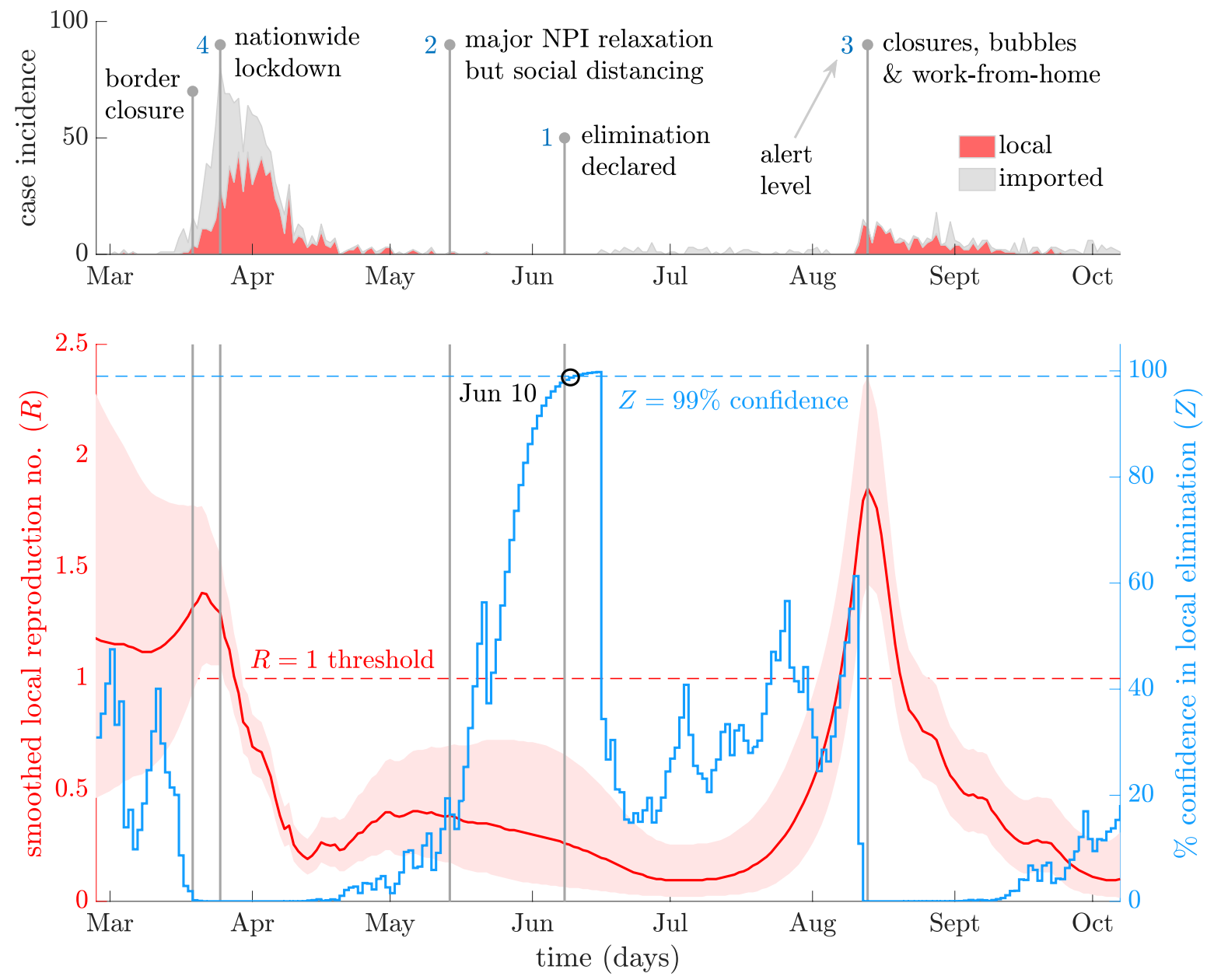

Figure 1: Local transmission dynamics of COVID-19 in New Zealand. The top panel plots local (red) and imported (grey, stacked) cases by date reported, sourced from [21]. Vertical lines pinpoint key policy change-times and alert levels (blue numbers) in response to these caseloads. The bottom panel presents smoothed local $R$ number estimates (red with 95\% confidence bands) and $Z$ numbers (blue), which measure $\%$ elimination potential. 
medRxiv preprint doi: https://doi.org/10.1101/2020.11.23.20236968; this version posted July 9, 2021. The copyright holder for this preprint

Applying our $R-Z$ approach, we demonstrate how NPI decision-times align with community transmission in Figure 1 (bottom). Initially, there was notable uncertainty around $R$ suggesting either supercritical or subcritical transmission could occur. The early response of New Zealand likely suppressed the first possibility, confidently forcing $R$ under 1 , post-lockdown. Swift action here was potentially critical as delayed responses in other countries have been correlated with larger epidemic sizes. An $R<1$ was sustained for a significant period after most NPIs were relaxed. Naïve $R$-estimates, which ignore local-import case divisions, would falsely predict $R$ $>1$ across much of this period (see Supplement). This naïve $R$, which is often presented in COVID-19 analyses and dashboards [1,3], could mislead policymakers.

Post-relaxation, the $Z$ number, which characterises risks to elimination from both imported and local cases, increased, suggesting the first wave could be declared over with $99 \%$ certainty by June 10. This corroborates the official declaration on June 9 [20]. Subsequently, recurrent introductions seeded new outbreaks, which led to the $R$-estimate climbing confidently above 1 just before the resurgence action-point. This steep rise in $R$ (and fall of $Z$ ) highlights that not only was a second wave likely but also that its transmission potential was larger than the first. The timely, unequivocal response of New Zealand in August likely averted a more explosive second epidemic, correlating with suppressed community transmission. The observed sharp decline in $R$ and its remaining below 1 evidences the efficacy of this policy and supports the belief that New Zealand regained control of COVID-19 in early October.

\section{Partial elimination and multiple waves in Hong Kong, China}

Upon learning of the SARS-CoV-2 outbreak in Wuhan, Hong Kong acted quickly, mobilising intensive surveillance schemes and declaring a state of emergency on January 25, 2020 in response to initial cases [22]. This involved closing amusement parks and suspending school reopening, which together with further NPIs enacted throughout February, likely suppressed wave 1. However, wave 2 began in March with many imported cases from North America and Europe, prompting strict border-closures on March 25 and bans on major public gatherings on March 29. Following these and other measures (e.g., venue closures) across April, incidence reduced. Consequently, NPIs were relaxed gradually from May 5-27. While imported cases continued to be recorded 21 days passed with no local cases observed, ending on July 5 [23].

Wave 3 soon surfaced with multiple, local infection-clusters in early July sharply increasing incidence. Consequently, mask mandates and social distancing controls were introduced on July 13 with additional measures enforced by July 19. Further tightening of these measures later in July eventually mitigated the wave, allowing NPI relaxations in September. Incidence was sustained at a low-level for two months before another resurgence occurred as wave 4 
medRxiv preprint doi: https://doi.org/10.1101/2020.11.23.20236968; this version posted July 9 , 2021. The copyright holder for this preprint (which was not certified by peer review) is the author/funder, who has granted medRxiv a license to display the preprint in perpetuity. It is made available under a CC-BY-NC-ND 4.0 International license .

on 24 November (with NPIs re-applied), the last date we analyse. Figure 2 (top) plots this timeline, with data from [6]. Although Hong Kong's response is less discretised than New Zealand's, our $R-Z$ framework still reveals sharp correlations between NPIs and salient transmission dynamics, as illustrated in Figure 2 (bottom).
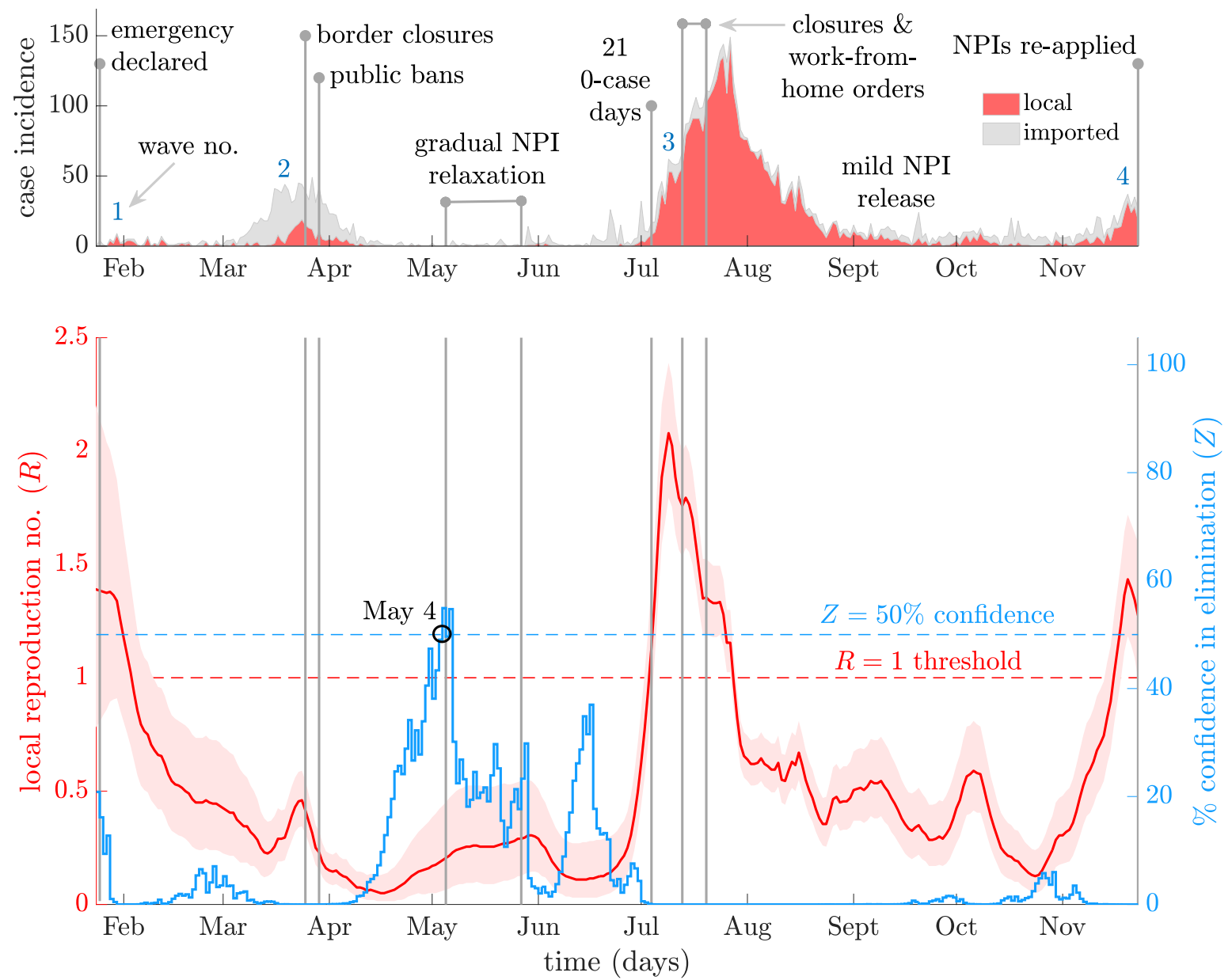

Figure 2: Local transmission dynamics of COVID-19 in Hong Kong, China. The top panel presents local cases (red) and imported cases (grey, stacked) by onset date from [6]. Vertical lines demarcate key policy change-times and responses (blue numbers indicate waves). The bottom panel plots smoothed local $R$-estimates (red with $95 \%$ confidence bands) and associated $Z$ numbers (blue) measuring the \% likelihood of elimination.

Initially, we infer a largely supercritical $R$ that appears to fall swiftly in response to emergency NPIs that were engaged without delay. This potentially minimised the size of wave 1 (subject to diagnostic testing rates). Subcritical transmission followed across wave 2, making the strategic border closures apt and effective and suggesting that this wave was not allowed to become a genuine resurgence. Intriguingly, soon after $Z$ starts to increase, achieving $55 \%$ in early May. Genetic data indicate that between waves 2 and 3 there was elimination of one circulating strain of SARS-CoV-2 (personal communication, B Cowling). The peaking of our $Z$ 
medRxiv preprint doi: https://doi.org/10.1101/2020.11.23.20236968; this version posted July 9 , 2021. The copyright holder for this preprint

number might reflect this, with co-circulating lineages preventing complete viral elimination. The weak transmission we infer in May-June supports the NPI relaxation that occurred. Interestingly, we find no evidence of increasing elimination potential in July.

This belies what might be naively expected, given that zero local cases were recorded for 21 consecutive days, which is 7 days below the WHO elimination criterion. However, on that $21^{\text {st }}$ day we infer $Z \approx 0 \%$, emphasising the utility of end-of-epidemic metrics that consider the localimport transmission context [15]. After this decrease in $Z$, our framework confidently signals supercritical community transmission, which likely created a large wave 3 . The steep rise in $R$-estimates is already underway by that $21^{\text {st }} 0$-case day, showing how maximally informed outbreak analytics can help decipher transmission signals, which are unclear from case-data. We infer change-points in $R$ that correlate with timing of key NPIs and find that those measures eventually constrict COVID-19 spread ( $R<1$ in August). As wave 3 wanes we obtain evidence supporting the NPI release from September ( $R$ declines) but then flag another confident rise in transmission in late November. This coincides well with the wave 4 declaration.

\section{Resurgence and eventual elimination in Victoria state, Australia}

Australia reported its first cases of community transmission on March 2, 2020. Victoria state, where many cases were beginning to concentrate, declared a state of emergency on March 16, which included stay at home orders and many activity restrictions. Further, all Australian borders were closed on March 20. This likely reduced both community-spread and capped the influence of imported cases in April, minimising the initial wave. As cases declined NPIs were adaptively relaxed and re-introduced across May and June. While a large case-cluster was discovered across May 2-14, linked to a meat packing plant and contributing the majority of infections in that time-period, swift contact-tracing and quarantines contained its impact [24]. However, the relaxation of household mixing NPIs resulted in large household gatherings that led to a rise in local cases. Victoria responded with postcode-based lockdowns by 30 June.

However, this was not sufficient and local cases burgeoned. NPIs were ramped up throughout July but the second wave grew exponentially. A 4-stage restriction policy with a target of zero community transmission was enacted and reinforced, building to a major lockdown (stage 4) on August 2 [24]. A state of disaster was also declared. Restrictions included confinement at home, curfews and closures. Slowly this large wave subsided and over 100 days after, NPIs began being relaxed from October 18 (stage 3). Staged re-opening continued until November 22 (stage 1), when most restrictions were removed. By November 27, the last time-point we consider, Victoria state had recorded 28 days of 0 -cases and declared elimination of SARS- 
medRxiv preprint doi: https://doi.org/10.1101/2020.11.23.20236968; this version posted July 9, 2021. The copyright holder for this preprint (which was not certified by peer review) is the author/funder, who has granted medRxiv a license to display the preprint in perpetuity. It is made available under a CC-BY-NC-ND 4.0 International license .

CoV-2. This timeline and the epidemic curve are given in Figure 3 (top), with data from [25]. We now investigate the transmission dynamics underlying this data using our $R-Z$ framework.
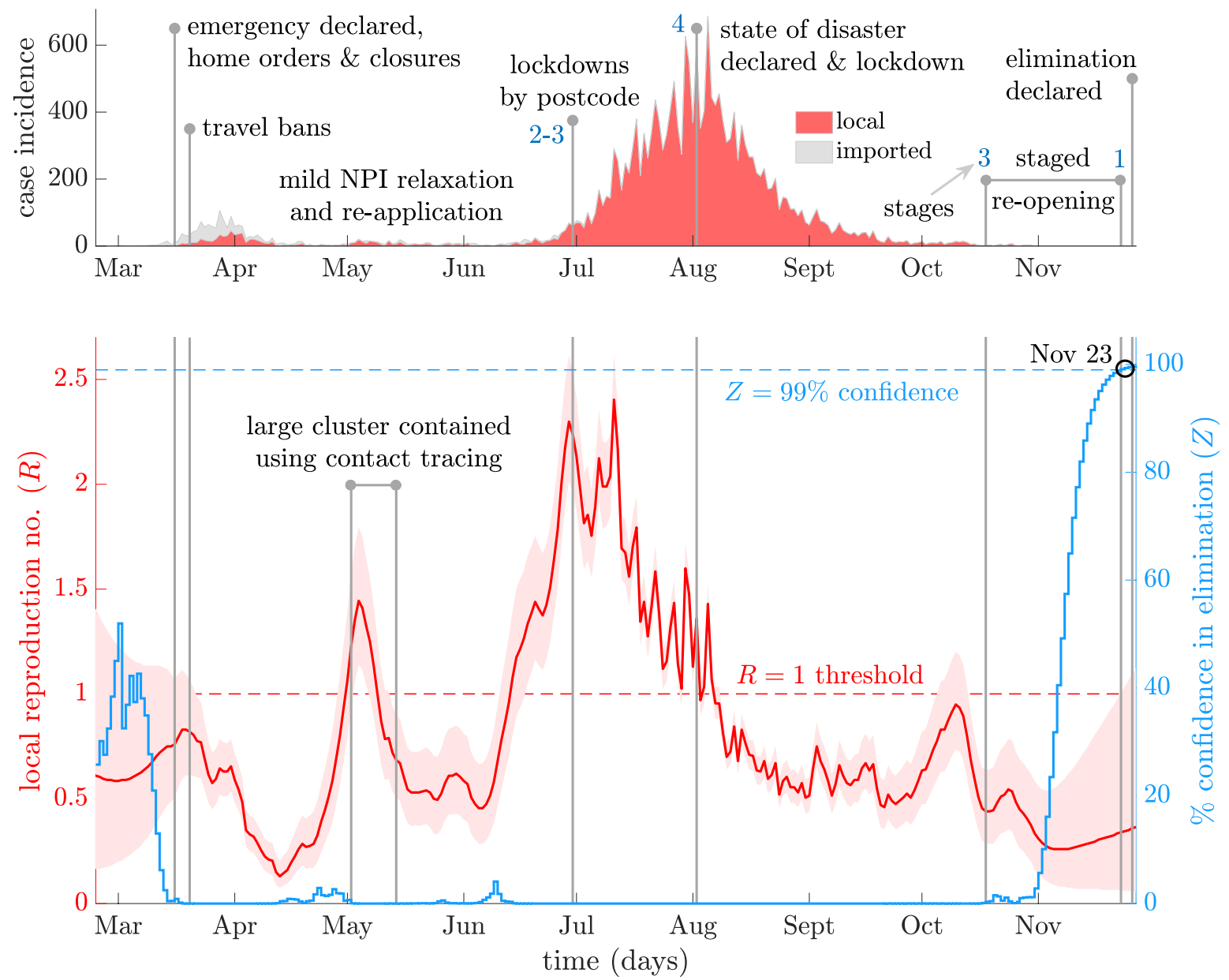

Figure 3: Local transmission dynamics of COVID-19 in Victoria, Australia. The top panel illustrates local (red) and imported (grey, stacked) cases by diagnosis date from [25]. Vertical lines highlight important policy change-times and responses (blue numbers are NPI restriction stages). The bottom panel presents smoothed local $R$-estimates (red with 95\% confidence bands) and resulting $Z$ numbers (blue) measuring the \% probability of elimination.

Our main results are displayed in Figure 3 (bottom). We find a slow start to the initial wave in Victoria with the confidence region of $R$ only partially above $1, Z$ at moderate levels and most cases being imported. However, $Z=0 \%$ quickly occurs and $R$ begins to increase. The speedy declaration of emergency and travel ban precede a clear downward trend in our $R$-estimates associated with suppression of this wave. This could have been especially effective since the majority of cases then were imported. Following this local $R$ remains subcritical, corroborating Victoria's adaptive NPI relaxation. We observe a large swing in our $R$-estimates that roughly aligns with the meat-packing plant cluster. The rapid peak and fall in $R$ likely reflect the contact- 
medRxiv preprint doi: https://doi.org/10.1101/2020.11.23.20236968; this version posted July 9, 2021. The copyright holder for this preprint (which was not certified by peer review) is the author/funder, who has granted medRxiv a license to display the preprint in perpetuity. It is made available under a CC-BY-NC-ND 4.0 International license .

tracing employed on this single cluster, which forms most cases in this period. Consequently, no true resurgence occurs, until a month later when our $R$-estimates rapidly elevate.

This provides early warning of the explosive second wave. The much larger local $R$ observed here suggests this period was the most critical for COVID-19 transmission in Victoria. Steadily harsher NPIs (from stage 2 to stage 4) are supported and correspond to $R$ falling below 1 . This fall is slower than its initial rise, expressing how larger-sized epidemics can be difficult to control and evidencing the necessity of sustained lockdown. Transmission remains subcritical throughout most of September and October. The stifled community-spread corroborates the staged-reopening strategy. As cases continue to fall our local $Z$ increases, also supporting NPI relaxation. We obtain $Z \approx 99 \%$ by November 23 , which favours NPI relaxation (stage 1 ), bolsters evidence for the success of Victoria's elimination-based strategy and suggests that we have almost $100 \%$ confidence in the official end-of-epidemic declaration.

Table 1: Alignment of NPIs with inferred $R-Z$ metrics. We summarise how the timing of key NPI applications and relaxations as well as official declarations of elimination correlate and correlate with salient transmission dynamics, as estimated under our $R-Z$ framework for COVID-19 in New Zealand, Hong Kong, China and Victoria state, Australia (Figures 1-3).

\begin{tabular}{|c|c|c|}
\hline New Zealand & Policy actions and details & Early-warning $R-Z$ evidence \\
\hline Mar 19-26 & $\begin{array}{l}\text { Border closures, nationwide } \\
\text { lockdown and alert level } 4 \text {. }\end{array}$ & $\begin{array}{l}R=1.32(0.94,1.78) \text { at action-point. Falls } \\
\text { to } 1.18(0.97,1.41) \text { after } 1 \text { week and then } \\
0.68(0.56,0.82) \text { at } 2 \text { weeks. }\end{array}$ \\
\hline May 14-Jun 9 & $\begin{array}{l}\text { Relaxation of some controls, } \\
\text { de-escalation to alert level } 2 \text {. }\end{array}$ & $\begin{array}{l}\text { At beginning and end of period } R=0.38 \\
(0.17,0.70) \text { and } 0.25(0.06,0.64) \text {. In period } \\
\text { it is comfortably below } 1 .\end{array}$ \\
\hline Jun 9 & $\begin{array}{l}\text { End-of-epidemic declaration } \\
\text { (WHO criteria - } 28 \text { days of } \\
\text { no cases), alert level } 1 .\end{array}$ & $\begin{array}{l}Z=98.7 \% \text { at declaration. From Jun } 5-15 \text { it } \\
\text { rises from } 96.1 \% \text { to } 99.8 \% \text {. A declaration } \\
\text { within this time is at least } 95 \% \text { certain. } \\
\text { Rapid fall to } Z=26.7 \% \text { on Jun } 16 \text {. }\end{array}$ \\
\hline Aug 12 & $\begin{array}{l}\text { Work at home, closures and } \\
\text { bubbles. Alert levels } 2-3 \text {. }\end{array}$ & $\begin{array}{l}\text { At action-point } R=1.80(1.36,2.31) \text {. Falls } \\
\text { to } 1.15(0.88,1.47) 1 \text { week later and } 0.75 \\
(0.54,1.00) \text { after } 2 \text { weeks. }\end{array}$ \\
\hline
\end{tabular}

Hong Kong Policy actions and details Early-warning $R-Z$ evidence 

Jan $25 \quad$ Wave 1 , state of emergency $R=1.38(0.80,2.14)$ at action-point. declared, NPIs enforced Falls to $1.17(0.80,1.63)$ after 1 week and e.g., schools kept closed then $0.75(0.49,1.07)$ at 2 weeks.
Mar 25-29 Wave 2, border closures and $R=0.41(0.31,0.54)$ on Mar 25. Reduces bans on public gatherings. to $0.12(0.07,0.20)$ and then $0.06(0.02$, $0.13)$ at 1 and 2 weeks after Mar 29.

May 4, Jul 5 Extinction of a SARS-CoV-2 Z $=54.9 \%$ on May 4 and on average $47.2 \%$ lineage (in May), 21 days of across Apr 29-May 6. Partial possibility of no local cases Jul 5). elimination in this period. $Z=0.02 \%$ on Jul 5 - effectively no chance of elimination.

May 5-27

NPIs gradually relaxed. Lull At beginning and end of period $R=0.20$ between potential waves. $(0.07,0.45)$ and $0.29(0.12,0.54)$. In period it is comfortably below 1 .

Jul 13-19

Sept 1-Nov 1

Wave 3, work-from-home $R=1.76(1.53,2.00)$ at first action-point. orders, venue closures and Falls to $1.15(1.02,1.30)$ and $0.62(0.52$, social distancing measures. $\quad 0.72) 1$ and 2 weeks after Jul 19.

Gradual relaxation of NPIs At beginning and end of period $R=0.50$ $(0.37,0.67)$ and $0.30(0.18,0.48)$ and never above 1 throughout.

Nov 23

Wave 4 , NPIs re-imposed. $R=1.27(0.99,1.59)$ at action-point. EarlyLast point analysed. warning of wave of local transmission.

\section{Victoria state Policy actions and details Early-warning $R-Z$ evidence}

Mar 16-20

May 2-14

Stay-at-home orders, state $R$ rises from $0.76(0.50,1.08)$ to 0.82 of emergency declared. $(0.61,1.06)$ across period. After $1-2$ weeks Added national travel bans. $\quad$ it is $0.59(0.48,0.74)$ and $0.48(0.39,0.60)$. Large cluster of cases from At beginning of period $R=1.22(0.93,1.57)$. meat packing plant. Contact It falls to $0.68(0.50,0.90)$ by the end. NPIs tracing and isolation applied. seem effective.

Jun 30 Adaptive lockdowns, stage $2 \quad R=2.24(1.96,2.53)$ at point applied. Falls and 3 restrictions engaged. to $2.12(1.91,2.35)$ and $1.67(1.52,1.83)$ after 1-2 weeks. Further NPIs needed.

Aug 2

Complete lockdown, stage $4 \quad R=1.35(1.26,1.45)$ at action-point. Might restrictions. State of disaster be larger due to noise in cases here. Falls officially declared. to $0.81(0.74,0.88)$ and $0.71(0.64,0.78)$ at 1 and 2 weeks after imposition. 
medRxiv preprint doi: https://doi.org/10.1101/2020.11.23.20236968; this version posted July 9, 2021. The copyright holder for this preprint

Oct 18-Nov 22 Gradual NPI release, from At beginning and end of period $R=0.44$ stages 3 to 1 . $(0.28,0.63)$ and $0.33(0.07,0.97)$. In period it remains safely below 1 .

Nov 27

End-of-epidemic declaration $Z=99.7 \%$ at declaration. From Nov $17-27$

(WHO criteria - 28 days of it rises from $95.0 \%$ to $99.1 \%$. A declaration no cases), alert level $1 . \quad$ within this period is at least $95 \%$ certain.

\section{Discussion}

Understanding the transmission forces underpinning epidemic elimination and resurgence is critical to the efficient design and timely implementation of NPIs. Appropriate responses to import-driven versus locally sustained outbreaks can differ markedly and materially given the constraints on resources. While naïve $R$-estimates and cross-country comparisons have been popularised across the COVID-19 pandemic, we argue that locally relevant strategies tuned to the specific dynamics of an area are imperative. Our proposed early-warning $R$ - $Z$ framework can support this aim, especially in the crucial data-limited lull between potential epidemic waves, where it significantly improves our ability to reliably denoise transmission change-point signals and decipher indicators of upcoming epidemic dynamics [16].

We attained this improvement by harnessing methodology from signal processing and control engineering [17]. Common $R$-estimators only exploit some of the information encoded within incidence data. Our Markovian smoothed $R$ applies forward-backward algorithms aimed at maximum information extraction (see Methods). This can double statistical efficiency in some instances [19]. Combining this methodology with local-import models [13], we derived a local $R$-estimator that is robust at small incidence and identifies change-points naturally. Reliable change-point detection can be problematic for existing estimators [9], while limited robustness hinders inference of elimination likelihoods [15]. Our $R$ (Eq.1) allowed us to devise $Z$ (Eq.2), a new metric for ascertaining the confidence in elimination that overcomes this issue.

We showcased our $R-Z$ framework on important and diverse COVID-19 case-studies (see Results). New Zealand, Hong Kong and Victoria state have presented difficulties to standard analyses due to prolonged low-incidence durations and large imported case numbers [1,3-6]. Although the categorisation and types of NPIs used differ, our analyses present clear evidence for the effectiveness and timeliness of the strategies employed in all three regions of study (Table 1). We inferred sharp correlations between downward transitions in $R$ and the timing of key NPIs, with major $R$ reductions seen after 2 weeks of sustained NPI usage. We estimated that the swiftness of NPI enforcements in several instances, such as New Zealand's second wave and Hong Kong's first wave, may have averted more explosive resurgence, as illustrated 

medRxiv preprint doi: https://doi.org/10.1101/2020.11.23.20236968; this version posted July 9,2021 . The copyright holder for this preprint
(which was not certified by peer review) is the author/funder, who has granted medRxiv a license to display the preprint in perpetuity. It is made available under a CC-BY-NC-ND 4.0 International license.

by clear $R$ turning points. We also found that NPIs were often sustained until local transmission was suppressed, supporting the choice of their relaxation or release.

However, while effective, the responses of our study regions were not all perfect. We observed right skew in the dynamics of $R$ - its growth was generally faster than its decay - accentuating the need for rapid NPI application. Hong Kong's third wave and Victoria's second wave both had notable periods over which $R$ climbed steadily above 1 . Imposing NPIs 1-2 weeks earlier might have appreciably reduced the epidemic burden in these cases. Stricter handling of imported cases may also be important going forward, as several subsequent waves were kickstarted by repeated introductions. Hong Kong's second wave and Victoria's first wave, which featured early travel bans and closures that suppressed the influence of many imported cases, might serve as a good template for handling such scenarios.

New Zealand and Victoria state both initiated and successfully implemented elimination-based strategies. We inferred $Z \approx 99 \%$ confidence in the end-of-epidemic declarations made by both regions, rigorously backing those decisions. We estimated that Hong Kong attained $Z \approx 50$ $55 \%$ in synchrony with the believed extinction of one circulating SARS-CoV-2 strain. Cocirculating lineages may have prevented the achievement of elimination. We observed $Z \approx 0 \%$ despite sustained $R<1$ in many periods, highlighting the insufficiency of $R$ for assessing elimination. Maintaining NPIs until Z crosses some threshold could be one data-informed way of deciding when to safely relax measures. Overall, we conclude that all regions responded decisively and adaptively to fluctuating local transmission. This conclusion is not wellsupported by more naïve $R$-estimates that neglect local-import models or non-smoothed ones that fail to use all the information in the incidence data (see Supplement for these analyses).

While our results provide rigorous underpinning and insight into COVID-19 dynamics in New Zealand, Hong Kong and Victoria, there are limitations. We do not explicitly compensate for reporting delays or under-reporting. However, these issues are likely minimised by the high fidelity of surveillance, contact-tracing and testing in our case-studies. Hong Kong had rapid screening systems ready due to past experiences with SARS in 2003 [22], while aggressive testing strategies in New Zealand and Australia have garnered praise [24]. Delays from symptom-onset to case notification in New Zealand are just 1.7 days, for example [20]. Moreover, we obtained strong one-step-ahead predictive fits (see Supplement), indicating model adequacy [9]. We also do not factor in time-varying serial intervals [26] or asymptomatic spread. However, limited data on these preclude improvement of our estimates. 
medRxiv preprint doi: https://doi.org/10.1101/2020.11.23.20236968; this version posted July 9,2021 . The copyright holder for this preprint

If, for some location of interest, these biases are known to be significant and relevant data (for example on reporting and serial interval fluctuations) are available then we recommend first compensating for these biases, to derive the best possible incidence curve, and then applying our framework. Delays can be resolved via deconvolution algorithms or simple shifting [27], while up-to-date serial intervals can be incorporated directly within our methodology. Underascertainment, asymptomatic spread and problems with approximating the generation time by the serial interval (see Methods) are more difficult to correct but solutions are actively being researched [28]. Note that early-warning signals are fundamentally not possible if outbreak monitoring is poor (e.g., large latencies to case notification). We envision our framework as supplementing outbreak analytics toolkits of regions with dedicated surveillance programmes.

Our $R$-Z framework is available in the EpiFilter package https://github.com/kpzoo/EpiFilter as a major extension. Although we analysed countries and regions, we expect our methodology to be particularly useful at finer scales, where incidence is necessarily smaller by division. There, reliable signalling of transmission change-points might support more targeted and less disruptive NPIs (e.g., postcode-lockdowns versus nationwide ones). Our method only requires clear classification of local and imported cases to remain valid, is reproducible and easy to run with minimal computational overhead. Early and robust warnings of resurgence or elimination can distinguish timely from tardy interventions. Local and contextualised metrics, such as $R$ $Z$, will hopefully help separate the signal from the noise, when it comes to effective NPIs.

\section{Methods}

The renewal transmission model is a popular and flexible means of modelling the spread of an infectious disease [29]. It describes how the number of new cases, i.e., the incidence, at time $s$, denoted $I_{s}$, depends on the effective reproduction number at that time, $R_{s}$, and the past incidence, which is summarised by the total infectiousness, $\Lambda_{s}$, as follows.

$$
\mathrm{P}\left(\mathrm{I}_{\mathrm{s}} \mid \mathrm{R}_{\mathrm{s}}, \mathrm{I}_{1}^{\mathrm{S}-1}\right) \equiv \operatorname{Pois}\left(\mathrm{R}_{\mathrm{s}} \Lambda_{\mathrm{s}}\right), \quad \Lambda_{\mathrm{s}}=\sum_{\mathrm{u}=1}^{\mathrm{s}-1} \mathrm{w}_{\mathrm{u}} \mathrm{I}_{\mathrm{s}-\mathrm{u}}
$$

Here Pois indicates Poisson, $\equiv$ denotes equality in distribution and $w_{u}$ is the probability that it takes $u$ days between the time of infection of a primary and secondary case. We consider incidence curves observed over times $1 \leq \mathrm{s} \leq \mathrm{t}$ with $\mathrm{I}_{\mathrm{a}}^{\mathrm{b}}$ as the portion $\left\{\mathrm{I}_{\mathrm{a}}, \mathrm{I}_{\mathrm{a}+1}, \ldots, \mathrm{I}_{\mathrm{b}}\right\}$.

The $w_{u}$ for all $u$ define the generation time distribution of the infectious disease of interest. We make the standard assumption that this distribution is known and well approximated by the serial interval distribution [7]. For the SARS-CoV-2 virus we use $\operatorname{Gam}(2.37,2.74)$ [30], which 
medRxiv preprint doi: https://doi.org/10.1101/2020.11.23.20236968; this version posted July 9,2021 . The copyright holder for this preprint

has a mean of 6.5 days. However, we find our key results are robust to other estimated SARSCoV-2 serial interval distributions [31]. While we do not account for possible changes to the serial interval distribution (e.g. contractions due to interventions [26]) or for temporal variations in case ascertainment [15], this remains valid if those changes are known and included [7].

Since time-varying reproduction numbers are likely to be autocorrelated [32], we generalise the renewal model to include a minimal, Markov random-walk assumption. The subsequent dynamical state model results, with Norm representing normally distributed noise.

$$
\mathrm{R}_{\mathrm{s}}=\mathrm{R}_{\mathrm{s}-1}+\left(\eta \sqrt{\mathrm{R}_{\mathrm{s}-1}}\right) \epsilon_{\mathrm{s}-1}, \quad \mathrm{P}\left(\epsilon_{\mathrm{s}-1}\right) \equiv \operatorname{Norm}(0,1) .
$$

Here $\eta$ is a state noise parameter, which is easy to tune and set to 0.1 in all analyses [16]. We validate this choice using causal one-step-ahead predictive fits (see Supplement) $[9,33]$. Our state noise also models some heterogeneous transmission, which is a key characteristic of many infectious diseases, including SARS-CoV-2 [32,34].

Our description offers two main advantages. First, we do not need to specify pre-determined change-points or averaging windows as in many popular approaches (e.g. EpiEstim [7,35]). Inference of $R$ is known to be highly sensitive to window-size and change-times choices $[8,9]$ Second, because we only make minimal state-assumptions, our estimates are less controlled by prior model assumptions [36]. Using these equations as is, however, only yields naïve $R$ estimates, as no distinction has yet been made between local and imported cases.

To incorporate case introductions, we apply a key decomposition [13]. If $L_{S}$ is the number of local cases at $s$ and $M_{s}$ the imported ones, then $I_{s}=L_{s}+M_{s}$. Both types of cases drive future local infections and so the transmission model is extended [18].

$$
\mathrm{P}\left(\mathrm{L}_{\mathrm{s}} \mid \mathrm{R}_{\mathrm{s}}, \mathrm{I}_{1}^{\mathrm{s}-1}\right) \equiv \operatorname{Pois}\left(\mathrm{R}_{\mathrm{s}} \Lambda_{\mathrm{s}}\right), \quad \Lambda_{\mathrm{s}}=\sum_{\mathrm{u}=1}^{\mathrm{s}-1} \mathrm{w}_{\mathrm{u}}\left(\mathrm{L}_{\mathrm{s}-\mathrm{u}}+\mathrm{M}_{\mathrm{s}-\mathrm{u}}\right)
$$

The state model is unchanged but now describes the evolution of local reproduction numbers. We next outline how to obtain $R$-estimates from the above transmission and state models that improve the robustness and reliability of inference when incidence is small.

We can construct three possible posterior distributions to describe how information from an observed incidence time-series is recruited to form estimates of $R_{s}$. These are known as the filtering $\left(\mathbf{p}_{\mathbf{s}}\right)$, predictive $\left(\mathbf{r}_{\mathbf{s}}\right)$ and smoothing $\left(\mathbf{q}_{\mathbf{s}}\right)$ posterior distributions.

$$
\mathbf{p}_{\mathbf{s}}=\mathrm{P}\left(\mathrm{R}_{\mathrm{s}} \mid \mathrm{I}_{1}^{\mathrm{s}}\right), \quad \mathbf{r}_{\mathbf{s}}=\mathrm{P}\left(\mathrm{R}_{\mathrm{s}} \mid \mathrm{I}_{\mathrm{s}}^{\mathrm{t}}\right), \quad \mathbf{q}_{\mathrm{s}}=\mathrm{P}\left(\mathrm{R}_{\mathrm{s}} \mid \mathrm{I}_{1}^{\mathrm{t}}\right) .
$$


medRxiv preprint doi: https://doi.org/10.1101/2020.11.23.20236968; this version posted July 9 , 2021. The copyright holder for this preprint (which was not certified by peer review) is the author/funder, who has granted medRxiv a license to display the preprint in perpetuity. It is made available under a CC-BY-NC-ND 4.0 International license .

These distributions are fundamental to any real-time or retrospective estimation problem and have been studied deeply in control systems engineering and signal processing $[17,37]$.

Standard inference methods either approximate $\mathbf{p}_{\mathbf{s}}$ (e.g., EpiEstim) or $\mathbf{r}_{\mathbf{s}}$ (e.g., the WallingaTeunis method [10]), which respectively incorporate past (backward) or "future" (forward) incidence information. In both instances, estimates suffer from edge-effects [7] and are more vulnerable to low-incidence periods because they cannot exploit all the available information $[16,19]$. This can be a significant limitation, especially in the important lull between potential epidemic waves, where data are scarce, but reliable estimates are vital for preparedness. A key contribution of this study is the computing of $\mathbf{q}_{\mathbf{s}}$ to derive smoothed, local $R$-estimates that formally utilise all incidence information up to s [17], under our generalised local-import model.

We achieve this by adapting recursive forward-backward Bayesian algorithms from [16]. First, we iteratively calculate $\mathbf{p}_{\mathbf{s}}$ (the forward pass) as below.

$$
\mathbf{p}_{\mathbf{s}} \propto \mathrm{P}\left(\mathrm{L}_{\mathrm{s}} \mid \mathrm{R}_{\mathrm{s}}, \mathrm{I}_{1}^{\mathrm{s}-1}\right) \psi_{\mathrm{s}}, \quad \psi_{\mathrm{s}}=\int \mathrm{P}\left(\mathrm{R}_{\mathrm{s}} \mid \mathrm{R}_{\mathrm{s}-1}, \mathrm{I}_{1}^{\mathrm{S}-1}\right) \mathbf{p}_{\mathrm{s}-1} \mathrm{dR}_{\mathrm{s}-1} .
$$

We apply a uniform prior distribution for $\mathbf{p}_{\mathbf{1}}$. The $\mathbf{p}_{\mathbf{s}}$ distributions are fed-back successively to then obtain $\mathbf{q}_{\mathbf{s}}$ (the backward pass) resulting in Eq.1, with $\mathbf{q}_{\mathbf{t}}=\mathbf{p}_{\mathbf{t}}$.

$$
\mathbf{q}_{\mathbf{s}}=\mathbf{p}_{\mathbf{s}} \int \mathrm{P}\left(\mathrm{R}_{\mathrm{s}+1} \mid \mathrm{R}_{\mathrm{s}}, \mathrm{I}_{1}^{\mathrm{s}}\right) \mathbf{q}_{\mathbf{s}+\mathbf{1}} \psi_{\mathrm{s}+1}^{-1} \mathrm{dR}_{\mathrm{s}+1} \text {. }
$$

By constructing $\mathbf{q}_{s}$ we maximise the information that is integrated into our local transmission estimates and minimise undue dependence on prior model choices and assumptions $[9,36]$.

This upgrades overall performance, when compared to common $R$-estimation methods, and significantly bolsters estimate robustness when incidence (or related) data are limited. These improvements follow because $\mathbf{q}_{s} \approx \propto \mathbf{r}_{s} \mathbf{p}_{\mathbf{s}} \mathrm{P}\left(\mathrm{R}_{\mathrm{s}}\right)^{-1}$ [16], meaning that it explicitly integrates information from both $\mathbf{p}_{\mathbf{s}}$ and $\mathbf{r}_{\mathbf{s}}$. Further details on these recursive algorithms are provided in $[17,37]$, where it is also noted that this formulation results in $R$-estimates that minimise mean squared estimation errors (relative to their "true" values). These estimates can be updated in real time as more data accumulate ( $t$ increases).

Our novel local $R$-estimates are functions of $\mathbf{q}_{s}$ (for example our mean estimate is $\int \mathbf{q}_{\mathbf{s}} \mathrm{R}_{\mathrm{s}} \mathrm{d} R_{S}$ ) that can decipher important early-warning signals of upcoming resurgence (see Results and Supplement) often buried in low-incidence data. However, this is not sufficient to assess the chance of local elimination. We therefore introduce the local, smoothed $Z$ number, a new 
medRxiv preprint doi: https://doi.org/10.1101/2020.11.23.20236968; this version posted July 9,2021 . The copyright holder for this preprint

measure of the statistical lifetime of the epidemic, which is obtained by generalising the recent theory from [15] to incorporate the $\mathbf{q}_{s}$ distribution from the import-local transmission model.

We define our \% confidence in an epidemic being eliminated (i.e., propagating no future local cases) at time $s$ as $Z_{s}=100 P\left(\sum_{u=s+1}^{\infty} L_{u}=0 \mid I_{1}^{s}\right)$, with $100-Z_{s}$ as the survival likelihood of at least one future case given existing data. We can solve for $\mathrm{Z}_{\mathrm{s}}$ by appending a pseudo stream of 0 -incidence values $\mathrm{I}_{\mathrm{S}+1}^{\infty}=\mathrm{L}_{\mathrm{S}+1}^{\infty}=0$ and then deriving posterior distributions over $\mathrm{R}_{\mathrm{s}+1}^{\infty}$ assuming these 0 -data. Expanding $Z_{s}$ sequentially we get the product below [15].

$$
\mathrm{Z}_{\mathrm{s}}=100 \prod_{\mathrm{u}=\mathrm{s}+1}^{\infty} \mathrm{P}\left(\mathrm{L}_{\mathrm{u}}=0 \mid \mathrm{I}_{1}^{\mathrm{s}}, \mathrm{I}_{\mathrm{s}+1}^{\mathrm{u}}=0\right) \text {. }
$$

Using the above local-import renewal model each term can be obtained as a function of $R_{u}$. Next, we marginalise over our $R$-distributions of interest, assuming the pseudo-data to obtain Eq.2, which together with Eq.1 forms our $R-Z$ framework.

$$
\mathrm{Z}_{\mathrm{s}}=100 \exp \left(-\sum_{\mathrm{u}=\mathrm{s}+1}^{\infty} \int \Lambda_{\mathrm{u}} \mathrm{R}_{\mathrm{u}} \mathbf{q}_{\mathrm{s}} \mathrm{dR}_{\mathrm{u}}\right)
$$

This $\mathbf{q}_{\mathbf{s}}$ is obtained from the same smoothing algorithms above but under the assumption that there are no future local cases. It is accordingly recomputed in real time for every $s$. We can also substitute $\mathbf{q}_{\mathbf{s}}$ with either $\mathbf{p}_{\mathbf{s}}$ or $\mathbf{r}_{\mathbf{s}}$ to obtain related elimination metrics.

Our $Z$ number quantifies the confidence that a local epidemic is over, given past incidence and in the presence of imported cases. This measure is more adaptive and telling than current WHO guidelines, which propose end-of-epidemic declarations based on fixed waiting times that relate to twice the incubation period of the infectious disease $[12,15]$. It also appreciably improves on previous metrics proposed in [15], which were limited by the destabilisation of $R$ at low incidence and unable to incorporate the uncertainty in local transmissibility.

Thus, our $R-Z$ framework makes minimal assumptions and can be applied in real-time to infer the upcoming risk of local transmission or the emerging likelihood of elimination. It can also be used retrospectively to discriminate among hypotheses surrounding the effectiveness and timeliness of previously implemented NPIs. Importantly, it remains valid at many scales of interest, e.g., countries or sub-regions of a state, provided local and imported cases are delineated. In this development we have assumed the availability of high-quality incidence data. If significant reporting delays and biases exist, these should be first compensated for (e.g., via deconvolution [27]) before applying our framework. 
medRxiv preprint doi: https://doi.org/10.1101/2020.11.23.20236968; this version posted July 9,2021 . The copyright holder for this preprint (which was not certified by peer review) is the author/funder, who has granted medRxiv a license to display the preprint in perpetuity. It is made available under a CC-BY-NC-ND 4.0 International license .

We showcase the power of this framework (both in real time and retrospectively) on three COVID-19 case-studies in the Results and Supplement. These examples all feature prolonged low-incidence periods that have destabilised standard inference methods [1,3-6]. Hopefully, our framework, by minimising the noise and maximising the informativeness of estimates, will help to better target and time NPI application and relaxation for a given region of interest. It is available as part of the EpiFilter package at: https://github.com/kpzoo/EpiFilter.

\section{Bibliography}

1. Li Y, Campbell H, Kulkarni D, Harpur A, Nundy M, Wang X, et al. The temporal association of introducing and lifting non-pharmaceutical interventions with the time-varying reproduction number $(\mathrm{R})$ of SARS-CoV-2: a modelling study across 131 countries. Lancet Infect Dis. 2020; doi:10.1016/S1473-3099(20)30785-4

2. De Serres G, Gay NJ, Farrington CP. Epidemiology of transmissible diseases after elimination. Am J Epidemiol. 2000;151: 1039-48; discussion 1049.

doi:10.1093/oxfordjournals.aje.a010145

3. Abbott $\mathrm{S}$, Helewell J, Thompson R, Others. Temporal variation in transmission during the COVID-19 outbreak. 2020;

4. COVID-19 Re [Internet]. [cited 1 Dec 2020]. Available: https://ibz-shiny.ethz.ch/covid-19-re/

5. COVID-19 Monitor [Internet]. [cited 1 Dec 2020]. Available: https://anevaluator.com.au/shiny/covid19_monitor/

6. Real-time dashboard [Internet]. [cited 1 Dec 2020]. Available: https://covid19.sph.hku.hk/

7. Cori A, Ferguson NM, Fraser C, Cauchemez S. A new framework and software to estimate time-varying reproduction numbers during epidemics. Am J Epidemiol. 2013;178: 15051512. doi:10.1093/aje/kwt133

8. Parag KV, Donnelly CA. Adaptive estimation for epidemic renewal and phylogenetic skyline models. Syst Biol. 2020;69: 1163-1179. doi:10.1093/sysbio/syaa035

9. Parag KV, Donnelly CA. Using information theory to optimise epidemic models for realtime prediction and estimation. PLoS Comput Biol. 2020;16: e1007990. doi:10.1371/journal.pcbi.1007990

10. Wallinga J, Teunis P. Different epidemic curves for severe acute respiratory syndrome reveal similar impacts of control measures. Am J Epidemiol. 2004;160: 509-516. doi:10.1093/aje/kwh255

11. Thompson R, Hollingsworth D, Isham V, Others. Key questions for modelling COVID-19 exit strategies. Proc R Soc B. 2020;287: 20201405.

12. Who. WHO recommended criteria for declaring the end of the Ebola virus disease outbreak. 2020;

13. Roberts MG, Nishiura $\mathrm{H}$. Early estimation of the reproduction number in the presence of imported cases: pandemic influenza H1N1-2009 in New Zealand. PLoS One. 2011;6: e17835. doi:10.1371/journal.pone.0017835

14. Nishiura H, Miyamatsu Y, Mizumoto K. Objective determination of end of MERS outbreak, South Korea. Emerg Infect Dis. 2016;22: 146-8.

15. Parag K, Donnelly C, Jha R, Thompson R. An exact method for quantifying the reliability of end-of-epidemic declarations in real time. PLOS Comput Biol. 2020; 16: e1008478.

16. Parag KV. Improved estimation of time-varying reproduction numbers at low case incidence and between epidemic waves. medRxiv. 2020; doi:10.1101/2020.09.14.20194589 
medRxiv preprint doi: https://doi.org/10.1101/2020.11.23.20236968; this version posted July 9,2021 . The copyright holder for this preprint (which was not certified by peer review) is the author/funder, who has granted medRxiv a license to display the preprint in perpetuity. It is made available under a CC-BY-NC-ND 4.0 International license .

17. Sarrka S. Bayesian Filtering and Smoothing. Cambridge, UK: Cambridge University Press; 2013.

18. Bourhy H, Nakouné E, Hall M, Nouvellet $P$, Lepelletier A, Talbi C, et al. Revealing the Micro-scale Signature of Endemic Zoonotic Disease Transmission in an African Urban Setting. PLoS Pathog. 2016;12: e1005525. doi:10.1371/journal.ppat.1005525

19. Guo D, Shamai S, Verdu S. Mutual Information and Minimum Mean-Square Error in Gaussian Channels. IEEE Trans Inform Theory. 2005;51: 1261-1282. doi:10.1109/TIT.2005.844072

20. Jefferies S, French N, Gilkison C, Graham G, Hope V, Marshall J, et al. COVID-19 in New Zealand and the impact of the national response: a descriptive epidemiological study. Lancet Public Health. 2020;5: e612-e623. doi:10.1016/S2468-2667(20)30225-5

21. COVID-19: Current cases | Ministry of Health NZ [Internet]. [cited 5 Dec 2020]. Available: https://www.health.govt.nz/our-work/diseases-and-conditions/covid-19-novelcoronavirus/covid-19-data-and-statistics/covid-19-current-cases

22. Cowling BJ, Ali ST, Ng TWY, Tsang TK, Li JCM, Fong MW, et al. Impact assessment of non-pharmaceutical interventions against coronavirus disease 2019 and influenza in Hong Kong: an observational study. Lancet Public Health. 2020;5: e279-e288. doi:10.1016/S2468-2667(20)30090-6

23. COVID-19 Timeline of Events - OT\&P Healthcare [Internet]. [cited 4 Dec 2020]. Available: https://www.otandp.com/covid-19-timeline

24. Department of Health and Human Services Victoria | Latest news and data - coronavirus (COVID-19) [Internet]. [cited 7 Dec 2020]. Available: https://www.dhhs.vic.gov.au/latestnews-and-data-coronavirus-covid-19

25. * Daily transmission sources in each state and territory | covid19data.com.au - Infogram [Internet]. [cited 7 Dec 2020]. Available: https://infogram.com/1pe22lpjkej3jrcm70wgk712zlalx09qk70?live

26. Ali ST, Wang L, Lau EHY, Xu X-K, Du Z, Wu Y, et al. Serial interval of SARS-CoV-2 was shortened over time by nonpharmaceutical interventions. Science. 2020;369: 1106-1109. doi:10.1126/science.abc9004

27. Goldstein E, Dushoff J, Ma J, Plotkin JB, Earn DJD, Lipsitch M. Reconstructing influenza incidence by deconvolution of daily mortality time series. Proc Natl Acad Sci USA. 2009;106: 21825-21829. doi:10.1073/pnas.0902958106

28. Ganyani T, Kremer C, Chen D, Torneri A, Faes C, Wallinga J, et al. Estimating the generation interval for coronavirus disease (COVID-19) based on symptom onset data, March 2020. Euro Surveill. 2020;25. doi:10.2807/1560-7917.ES.2020.25.17.2000257

29. Fraser $\mathrm{C}$. Estimating individual and household reproduction numbers in an emerging epidemic. PLoS One. 2007;2: e758. doi:10.1371/journal.pone.0000758

30. Ferguson N, Laydon D, Nedjati-Gilani G, Others. Impact of non-pharmaceutical interventions (NPIs) to reduce COVID- 19 mortality and healthcare demand. Imperial College London; 2020.

31. Nishiura H, Linton NM, Akhmetzhanov AR. Serial interval of novel coronavirus (COVID-19) infections. Int J Infect Dis. 2020;93: 284-286. doi:10.1016/j.ijid.2020.02.060

32. Yan P, Chowell G. Quantitative Methods for Investigating Infectious Disease Outbreaks. Cham, Switzerland: Springer; 2019.

33. Wagenmakers E-J, Grünwald P, Steyvers M. Accumulative prediction error and the selection of time series models. J Math Psychol. 2006;50: 149-166. doi:10.1016/j.jmp.2006.01.004

34. du Plessis L, McCrone JT, Zarebski AE, Hill V, Ruis C, Gutierrez B, et al. Establishment \& lineage dynamics of the SARS-CoV-2 epidemic in the UK. medRxiv. 2020; doi:10.1101/2020.10.23.20218446 
medRxiv preprint doi: https://doi.org/10.1101/2020.11.23.20236968; this version posted July 9,2021 . The copyright holder for this preprint (which was not certified by peer review) is the author/funder, who has granted medRxiv a license to display the preprint in perpetuity. It is made available under a CC-BY-NC-ND 4.0 International license.

35. Thompson RN, Stockwin JE, van Gaalen RD, Polonsky JA, Kamvar ZN, Demarsh PA, et al. Improved inference of time-varying reproduction numbers during infectious disease outbreaks. Epidemics. 2019;29: 100356. doi:10.1016/j.epidem.2019.100356

36. Parag KV, Pybus OG, Wu C-H. Are skyline plot-based demographic estimates overly dependent on smoothing prior assumptions? Syst Biol. 2020; doi:10.1093/sysbio/syab037.

37. Snyder D. Smoothing for Doubly Stochastic Poisson Processes. IEEE Transactions on Information Theory. 1972;18: 558-62.

\section{Funding}

KVP and CAD acknowledge joint centre funding from the UK Medical Research Council (MRC) and Department for International Development (DFID) under grant reference MR/R015600/1. CAD thanks the UK National Institute for Health Research Health Protection Research Unit (NIHR HPRU) in Emerging and Zoonotic Infections in partnership with Public Health England (PHE) for funding (grant HPRU200907). The funders had no role in study design, data collection and analysis, decision to publish, or preparation of the manuscript.

\section{Authors Contributions}

KVP and CAD conceptualised the study. KVP developed the software and methodology, performed the research and wrote the initial draft. KVP, BJC and CAD validated all results, analyses and methods. and wrote the final draft. 